\title{
CONFLITOS, COOPERAÇÃO E MEDIAÇÃO: ANÁLISE DA ATUAÇÃO DA COMISSÃO ESTADUAL DE PREVENÇÃO À VIOLÊNCIA NO CAMPO E NA CIDADE (COECV) COMO POLÍTICA DE MEDIAÇÃO DE LITÍGIOS POSSESSÓRIOS
}

\author{
Daniela Ferreira dos Reis ${ }^{1}$ \\ Vitor Hugo Souza Moraes ${ }^{2}$ \\ Arnaldo Vieira Sousa ${ }^{3}$
}

\section{RESUMO}

O presente artigo analisa a política de mediação de conflitos possessórios a partir dos trabalhos desenvolvidos pela COECV, no Maranhão. Estuda-se a judicialização dos conflitos e a violência no cumprimento de despejos. Em seguida, discute-se a mediação no contexto do Código de Processo Civil. Por fim, analisa-se a metodologia e funcionamento da COECV. Conclui-se que a Comissão inova ao aplicar metodologia de mediação frente à complexidade dos conflitos possessórios e à má distribuição de terras. Optou-se pelo método indutivo e abordagem qualitativa a partir de revisão bibliográfica do referencial teórico pertinente para análise dos documentos e dados públicos.

Palavras-chaves: Conflitos possessórios. Mediação de Conflitos. Políticas Públicas. Cooperação. COECV.

\section{CONFLICTS, COOPERATION AND MEDIATION: ANALYSIS OF THE PERFORMANCE OF THE STATE COMMISSION FOR THE PREVENTION OF VIOLENCE IN THE COUNTRY AND IN THE CITY (COECV) AS A POLICY OF MEDIATION IN POSSESSION DISPUTES}

\begin{abstract}
This article analyzes the policy of possessory mediation conflicts based on the work developed by COECV, in Maranhão. Judicialization of conflicts and violence in carrying out evictions are being studied. Mediation is discussed in the context of the Civil Procedure Code. Finally, the methodology and functioning of COECV is analyzed. It is concluded that the

\footnotetext{
${ }^{1}$ Advogada (OAB/MA). Assessor Jurídico na COECV. Especialista em Direito de Família, Infância e Juventude. Mestranda em Direitos Humanos, Cidadania e Políticas Públicas (PPGDH/UFPB). Graduada em Direito (UNDB). Membro do Grupo de Pesquisa Cultura, Direito e Sociedade (UFMA). Rua 20, Qd 13-A, Casa 10, Planalto Vinhais II, São Luís/MA, CEP 65074-877. E-mail: daniela.reisfr@gmail.com. ORCID: https://orcid.org/0000-0002-20285977.

${ }^{2}$ Advogado (OAB/MA). Assessor Jurídico na COECV. Especialista em Direito Público (PUC-MG). Mestrando em Direito e Instituições do Sistema de Justiça (UFMA). Pós-Graduando em Direitos Difusos e Coletivos (CERS). Pesquisador do Grupo de Pesquisa Cultura, Direito e Sociedade (UFMA). Graduado em Direito (UFMA). Av. dos Holandeses, 03, Qd 30, Edf Portal da Enseada, Apt 1002, Ponta D'areia. CEP 65077-357. E-mail: vitorhugosmoraes@gmail.com. ORCID: https://orcid.org/0000-0002-3863-7125.

${ }^{3}$ Advogado (OAB/MA). Professor (UNDB). Mestre e Doutor em Políticas Públicas (UFMA). Graduado em Direito (UFMA). Av. Mário Andreazza, Cond. Village das Palmeiras 3, bloco 2, apto 107. Turu - São Luís, MA. CEP 65068500. E-mail: vieira.arnaldo@gmail.com. ORCID: https://orcid.org/0000-0003-3526-5351.
} 
Commission innovates by applying mediation methodology in view of the complexity of possessory conflicts and the bad distribution of land. We opted for the inductive method and qualitative approach based on a bibliographic review of the relevant theoretical framework for the analysis of documents.

Keywords: Possessory conflicts. Conflict Mediation. Public policy. Cooperation. COECV.

\section{INTRODUÇÃO}

O contexto de conflitos possessórios marca os processos de ocupação das cidades brasileiras, em meio a má distribuição de terras e a especulação econômica, diversas pessoas são empurradas a uma vida de insegurança jurídica, à mercê de despejos e ações de reintegrações de posse.

O Estado do Maranhão, assim como muitos estados brasileiros, tem um histórico violento de ações de despejos e cumprimento de decisões judiciais contra as ocupações irregulares, com graves violações de direitos humanos.

Nesse contexto, desde o ano 2015, a partir da alteração do Código de Processo Civil, a mediação de conflitos assume um papel de maior protagonismo nos conflitos judiciais brasileiros e nas ações possessórias torna-se um importante instrumento para evitar injustiças decorrentes da precariedade das decisões liminares.

As audiências de justificação prévia, a participação obrigatória do Ministério Público e da Defensoria Pública nos conflitos envolvendo direitos coletivos demonstra a preocupação do legislador para que antes da realização das reintegrações de posse sejam viabilizadas as mediações e consequentemente, se garanta o direito à moradia das populações em vulnerabilidade social.

Aliado a essa perspectiva, o Governo do Estado do Maranhão a partir da Secretaria Estadual de Direitos Humanos e Participação Popular tem adotado uma política de mediação e prevenção de conflitos que tem por objetivo dar uma atuação ativa do Estado e de suas políticas públicas que não sejam meramente políticas para "remediar" os danos decorrentes dos processos de reintegração de posse. Por isso, o estudo questiona quais as contribuições da política pública de mediação e prevenção de conflitos na questão dos conflitos possessórios no Estado do Maranhão?

A partir da análise das políticas executadas pela Secretaria Estadual de Direitos Humanos e Participação Popular do Estado do Maranhão - SEDIHPOP, o estudo avança em 
reflexões sobre a complexidade das disputas que envolvem as ocupações coletivas nos espaços urbanos e como a mediação de conflitos tem sido utilizada para garantir os direitos humanos.

É de grande relevância o recorte, pois o Estado do Maranhão é pioneiro na execução da mediação de conflitos no âmbito do poder executivo, na perspectiva da mediação extrajudicial e tem demonstrado protagonismo no avanço de políticas em direitos humanos a partir da atuação com movimentos sociais e entidades representativas.

\section{OCUPAÇÃO DA TERRA E JUDICIALIZAÇÃO: Os conflitos possessórios e o contexto do Estado do Maranhão}

Os conflitos possessórios no Maranhão reproduzem as desigualdades enraizadas na ocupação do espaço urbano e expansão agrícola no Brasil, sendo necessário analisar o contexto das disputas jurídicas a partir do contexto de formação dos espaços urbanos e das cidades.

As famílias em vulnerabilidade social passaram por processos de expulsão das áreas rurais para a marginalização nas áreas urbanas. Sem recursos para acessar a "Cidade" e suas propriedades privadas economicamente valorizadas, os sujeitos se aglomeram nas ocupações irregulares ou "invasões", como resultado de um processo de resistência na busca pelo acesso à Cidade e moradia (LEFEBVRE, 2001).

Ermínia Maricato (2015, p.18) reflete que desde a revolução industrial o mundo passou a ser predominantemente urbano, e com isso os problemas da pobreza e da aglomeração nas cidades tornaram-se os problemas característicos do século XXI. A Cidade, portanto, reproduz a lógica produtiva do modo de produção capitalista, como enfatiza Lefebvre (2001), e nesse sentido os conflitos por terras, se reproduzem na lógica e na gestão desses espaços.

No Brasil, o espaço rural é "marcado pela concentração de terra, renda e poder, pelo exercício do coronelismo ou política do favor e pela aplicação arbitrária da lei" (MARICATO, 2015, p.16), o que associado a um processo de urbanização desorganizada cria uma estrutura política desligada da realidade social (SANTOS, 2018), e faz com que a 
organização da cidade seja determinada por uma marginalização e valorização econômica da terra, que cria espaços de irregularidade habitacional.

Segundo Pietro (2019), a propriedade privada surge oficialmente no arcabouço jurídico brasileiro com a Constituição de 1824 e a Lei de Terras de 1850, porém, ao mesmo tempo, em que se criou a legalização da propriedade, se legitimou a grilagem de terras, instituindo "confusões jurídicas", que estão intimamente relacionadas aos processos de disputas possessórias. Isso porque, tais instrumentos criaram o fundamento da propriedade absoluta, ao reconhecer a presunção jurídica para aqueles que já detivessem propriedade", na proteção dos cativos e dos que já detinham concessões legitimadas das sesmarias.

\begin{abstract}
As elites brasileiras, fundamentalmente regionalizadas, pactuaram simultaneamente duas formas de manutenção de seu poder: a continuação da utilização do trabalho escravo como motor da produção e das relações sociais e simultaneamente a regulação da propriedade privada, garantida como absoluta e, posteriormente, institucionalizada como mercadoria - ou seja, a permanência de fundos territoriais a serem apropriados privadamente. Essa forma de "ruptura incompleta" à brasileira vai consolidar a grilagem como um dos elementos de constituição do Estado nacional, forma mantida do sistema colonial. A intocabilidade da propriedade produziu uma forma associada de garantia dessa absolutização de apropriação e monopolização de terras: a desapropriação capitalista da terra, que deveria ser paga de forma prévia (PRIETO, 2019)
\end{abstract}

Santos (2018, p.78-79) aponta a "concentração da população e da pobreza, contemporânea da rarefação rural e da dispersão geográfica das classes médias", mantendo-se as características de divisão desigual de terra das Capitanias hereditárias, agora numa sistematização do êxodo rural que isola e solidifica as desigualdades sociais por meio da formação arbitrária das favelas e periferias.

Raquel Ronik, em “Guerra dos Lugares” (2015, p.150), aponta que a precariedade habitacional e as ambiguidades em relação à posse, enquanto pontos que definem os espaços de ocupação urbana das "favelas, assentamentos irregulares, assentamentos informais".

A posse em relação às questões de percepção de permanência e transitoriedade diferem sob muitos aspectos, e se reflete em uma "noção altamente enraizada no contexto político, econômico, jurídico e cultural de cada região e nação, e, portanto, marcada por dificuldades de definição" (ROLNIK, 2015, p.150).

Apesar da formação histórica dos espaços demonstrar que a maioria das áreas de ocupação urbana não possuem documentos de propriedade comprobatórios, e em grande medida, tais ocupações se deram de formas irregulares e se consolidaram em meio a cidade, 
destaca-se que os mais pobres e vulneráveis arcam com a maior parte do ônus decorrente dessa situação.

\begin{abstract}
Fundamentalmente, a insegurança da posse é uma questão de economia política leis, instituições e processos de tomada de decisão relacionados ao acesso e ao uso da moradia e da terra são atravessados pelas estruturas de poder existentes na sociedade. Assim, tanto as formas de gestão do solo como as estratégias de planejamento urbano têm uma enorme incidência sobre as possibilidades de acesso ou bloqueio - à terra urbanizada para os moradores de menor renda. É no interior desta trama jurídico-administrativa que se tecem os mecanismos de inclusão/exclusão na cidade (ROLNIK, 2015, p.151-152)
\end{abstract}

O conflito propriedade vs posse se instala nesse contexto, e é a partir da Constituição de 1988 que se tem a judicialização dos conflitos fundiários e o papel do Estado na execução das reintegrações de posse. A ONU (2005, p.8), fixou a terminologia de "desocupações forçadas" ou "despejos forçados" (forced evictions), para se referir as consequências da insegurança da posse no processo de "o afastamento involuntário de pessoas das suas casas ou terras, imputável, direta ou indiretamente, ao Estado" (ONU, 2005, p. 8). Entende-se por conflitos fundiários, segundo Resolução nº 87 de 2009, do Conselho das Cidades:

\footnotetext{
[...] disputa pela posse ou propriedade de imóvel urbano, bem como impacto de empreendimentos públicos e privados, envolvendo famílias de baixa renda ou grupos sociais vulneráveis que necessitem ou demandem a proteção do Estado na garantia do direito humano à moradia e à cidade (art. $3^{\circ}$, inciso I). (BRASIL, 2010).
}

Com a CF/1988, o Judiciário assume o protagonismo para resolução das disputas em prol de garantia de direitos, combate a ilegalidades e abusividades e resolver questões que deveriam ser solucionadas espontaneamente pelo Estado através de um sistema de bem-estar social efetivo (SANTOS, 2010, p.12-13).

Nesse sentido, Costa e Chai (2019) apontam que o crescimento do número de conflitos possessórios judicializados também revela um fortalecimento institucional democrático, uma vez que a "busca pela decisão judicial em muitos casos previne ou cria embaraços para uso da violência armada e ilegal para coagir e expulsar ocupantes".

As ações possessórias previstas a partir do art. 554 do $\mathrm{CPC}$, se dividem em Manutenção e da Reintegração de Posse e Interdito Proibitório, sendo objeto da manutenção ou reintegração os casos da turbação ou esbulho. Tartuce (2017) explica que enquanto na situação de ameaça não há qualquer ato concreto (mero risco), na turbação há atentado à posse de forma não definitiva e no esbulho o atentado ocorreu de modo definitivo. 
É a reintegração de posse portanto, que está no cerne da questão dos conflitos pela posse, pois os espaços urbanos ao serem ocupados, tem-se o reconhecimento da "perda da posse", e daí torna-se objeto da ação o retorno a esse exercício sobre o bem imóvel. Costa e Chai (2019) destacam que para o ajuizamento da reintegração de posse, não há necessidade de demonstrar a propriedade privada, mas sim o exercício da posse passada.

A relevância desse instrumento decorre da possibilidade da concessão de liminar de reintegração de posse, conforme art. 525 do CPC (BRASIL, 2015), a petição instruída com o demonstrativo da posse, o juiz pode, sem ouvir o réu, expedir o mandado liminar de manutenção ou de reintegração.

É importante destacar, que a comprovação da posse apesar de ser um conceito em disputa no Brasil, está intimamente ligada à função social da propriedade, uma vez que a Constituição Federal no art. 5, XXIII e 170, III condiciona que a proteção à propriedade é garantida àquela que atende a função social, que representa seu efetivo uso e finalidade com o interesse público.

Torres (2015, p.1378) ao analisar o entendimento da jurisprudência brasileira, demonstra que o descumprimento do dever social de proprietário significa uma "lesão ao direito fundamental de acesso à propriedade" e, portanto, não é coerente conceder as mesmas garantias a proteção do exercício do uso sobre a propriedade ao titular do domínio cuja propriedade não cumpra integralmente sua função social.

Nesse sentido, Costa e Chai (2019) apontam que as decisões liminares concedidas no âmbito das ações possessórias em conflitos agrários são problemáticas por não atenderem aos requisitos dispostos no $\mathrm{CPC}$ em relação a identificação do caráter coletivo, mas principalmente pela perda do caráter da irreversibilidade.

\footnotetext{
Neste sentido, pontua-se que medida liminar em casos de conflitos possessórios deve ser tratada com a devida cautela para fins de evitar os perigos da irreversibilidade e considerando também o impacto social da decisão que, nestes casos específicos, pode deixar famílias desabrigadas e sem terra para trabalho ou reprodução de suas práticas tradicionais (COSTA, CHAI, 2019, p. 90)
}

De fato, uma vez concedida a liminar de reintegração de posse, é autorizado o cumprimento e consequente quaisquer evidências materiais sobre a habitação e a relação do uso do espaço são destruídas, e não chegam a ser utilizados na análise do mérito dos processos. A urgência que caracteriza esses conflitos, decorre do fato de que na ausência de 
esforços para a retirada das ocupações, a perda da posse se consolida e autoriza a permanência.

Por essa complexidade é que o contexto das disputas fundiárias é marcado pela ação violenta, e no Estado do Maranhão é evidente que a instabilidade dos conflitos no campo reflete nas disputas nos espaços urbanos. Segundo dados do caderno de Conflitos no Campo divulgado pela Comissão Pastoral da Terra (CPT) em 2020, o Maranhão lidera o ranking de conflitos por terra no Brasil. Por sua vez, somente em 2020, em plena pandemia, a Federação dos Trabalhadores Rurais do Maranhão (FETAEMA) contabilizou 156 conflitos agrários envolvendo diretamente 9.126 famílias no estado (COECV, 2021).

Por isso, é necessário avançar em estratégias que levem em consideração a dinâmica de ocupação do espaço e a vulnerabilidade socioeconômica das pessoas envolvidas nessas ocupações irregulares. As ações possessórias tiveram significativas alterações no Código de Processo Civil de 2015, justamente para abarcar essas relações entre os conflitos e o risco da concessão das liminares sem a identificação dos requisitos corretos da posse.

\section{CONSENSUALIDADE, COOPERAÇÃO E MEDIAÇÃO: perspectivas do Código de Processo Civil para resolução de conflitos coletivos possessórios}

Desde quando promulgado a lei n. ${ }^{\circ} 13.105$ de 16 de março de 2015, o atual Código de Processo Civil (CPC), o tratamento do poder judiciário aos litígios precisou ser readequado aos parâmetros principiológicos inaugurados pela nova norma geral de processo, especialmente, os princípios da consensualidade e do acesso à justiça. É nesse sentido que a autocomposição, tão presente no texto do CPC, contribui para o tratamento adequado dos conflitos e apresenta-se como o futuro da justiça brasileira por meio da desjudicialização da própria vida (BARROSO, 2014, p. 9-10).

Quando se defende a proeminência de um novo princípio ${ }^{4}$ no âmbito do processo civil, embasa-se no conjunto de normas constitucionais e infraconstitucionais e na atual "Política Judiciária Nacional de tratamento dos conflitos de interesses, tendente a assegurar a

\footnotetext{
${ }^{4}$ Nesse sentido, entendem-se os princípios do CPC como fundamentos que embasam os fundamentos que embasam os procedimentos no processo civil. Conforme ALEXY (2008, p. 544), "a irradiação dos direitos fundamentais como direito positivo em todos os âmbitos do sistema jurídico inclui, portanto, uma irradiação requerida pelo direito positivo - da ideia de justiça a todos os ramos do direito".
} 
todos o direito à solução dos conflitos por meios adequados à sua natureza e peculiaridade" (BRASIL, 2010), especialmente, nos meios consensuais, como a conciliação e a mediação.

Desse modo, entende-se que o princípio da consensualidade não determina que todos os litígios regulados pelo direito processual civil sejam necessariamente resolvidos consensualmente. Esse princípio representa, na verdade, que a resolução dos conflitos deve primar pela autocomposição e, quando não for adequado à natureza e às peculiaridades do caso, deve-se recorrer à resolução por decisão judicial.

De forma concreta, o CPC sinaliza, em diversos momentos, a efetiva resolução dos interesses distintos de forma amigável. No art. 334, quando do recebimento de uma petição inicial, o Código já prevê a designação de audiência de conciliação ou mediação pelo juízo, a não ser quando ambas as partes se manifestarem pelo desinteresse na autocomposição $\left(\S 4^{\circ}\right)$. Entretanto, caso apenas uma das partes tenha sinalizado interesse na composição consensual, conforme o $\S 8^{\circ}$ do mesmo artigo, a ausência injustificada de uma das partes na audiência de mediação poderá ser considerado ato atentatório à dignidade da justiça, sendo sancionado com multa.

No contexto específico dos conflitos coletivos possessórios, a necessidade de se observar a possibilidade de resolução dos conflitos por meio dos métodos adequados ganha ainda mais relevo no texto do CPC. Especialmente para litígios dessa natureza, o artigo 565 do CPC prevê a realização de audiência de mediação com participação do Ministério Público; órgãos de política agrária e política urbana dos entes federativos; e a Defensoria Pública, caso haja pessoas hipossuficientes. Considerando-se, nesse caso, a clareza do texto e a consequente necessidade de interpretar a literalidade da norma, infere-se que o juiz da causa se encontra obrigado a designar audiência de mediação, não se tratando, portanto, de uma mera faculdade judicial (MELLO, 2017, p. 2076).

Enquanto nos litígios ordinários regulados pelo CPC basta a presença das partes, o art. 565 deixa evidente a necessidade de outros órgãos e instituições para buscar uma solução consensual. Essa ampla participação no processo de mediação revela que os conflitos coletivos pela posse superam os limites de uma simples controvérsia particular, "refletindo para dimensões política e social muito mais importantes. Supõe o legislador que, efetivamente, o Poder Público estará engajado nessa solução e poderá protagonizar resposta muito mais adequada do que a simples resolução judicial da controvérsia" (MARINONI; ARENHART; MITIDIERO, 2015, p. 176). 
A partir da análise do dispositivo mencionado, percebe-se que o princípio da consensualidade guarda relação com o princípio da cooperação, defendido por alguns autores e contraditado por outros ${ }^{5}$. A primeira aparição da cooperação no CPC aparece no art. $6^{\circ}$, no qual se estabelece que "todos os sujeitos do processo devem cooperar entre si para que se obtenha, em tempo razoável, decisão de mérito justa e efetiva". Nesse sentido, de fato, "os meios autocompositivos são, em sua essência, mecanismos cooperativos, no sentido de trazer participação das partes envolvidas para que colaborem para um diálogo equilibrado e esclarecedor, com o objetivo de solucionar o conflito" (POMPEU; MARTINS, 2018, p. 104).

Do mesmo modo, o Manual de mediação judicial do CNJ (AZEVEDO, 2016, p. 69) destaca que a relação de cooperação com a disputa de interesses em um litígio não pode ser tratada como um aspecto ético da conduta dos envolvidos, e sim sob um olhar de racionalidade voltado à otimização da resolução do conflito posto. Assim, entende-se que a consensualidade e a cooperação são elementos aliados, capazes de desenvolver um procedimento que proporcione às partes um sentimento de justiça, a despeito do resultado da demanda.

Destarte, à luz dessa compreensão principiológica, o art. 178, III do CPC determina que o órgão deve intervir, como fiscal da ordem jurídica, nos “[...] litígios coletivos pela posse da terra rural e urbana". Essa previsão atende à perspectiva de que há interesse público acerca da resolução dos conflitos coletivos pela posse da terra, visto que essa temática encontra sua origem no descumprimento inicial de direitos fundamentais, como o acesso à moradia.

Já ao tratar sobre as ações possessórias, o CPC prevê, nos artigos $554 \S 11^{\circ}$ e $565 \S$ 2. , a intimação ao Ministério Público para intervir nos conflitos. Assim, a atuação do órgão deve ser pautada pela necessidade de aplicar a lei processual e os preceitos constitucionais voltados para a realização do conteúdo social e programático da Constituição Federal. Nesse viés, tratando-se de ação em que figure uma coletividade no polo passivo, o Código Processual Civil aponta a obrigatoriedade de intimação do Ministério Público e da Defensoria

\footnotetext{
${ }^{5}$ Em oposição ao princípio da cooperação, STRECK et al. (2014) defende que cooperação não condiz com a realidade processual e que se trata de uma questão de moral no direito, possibilitando um "desmedido protagonismo judicial" por meio da cooperação. Contudo, entende-se, neste trabalho, que a cooperação para resolução de conflito, seja consensualmente ou por decisão judicial, não abdica necessariamente a direitos materiais e garantias processuais. Ao contrário, defende-se a utilização desse princípio "desde, é claro, que se sigam as normas e princípios processuais, sobretudo o da ampla defesa e contraditório, com garantia a segurança jurídica” (POMPEU; MARTINS, 2018, p. 106).
} 
Pública, neste último caso quando houver pessoas "em situação de hipossuficiência econômica".

A atuação da Defensoria Pública é relevante dado que os perfis dos moradores das ocupações coletivas, em sua maioria, são de pessoas em vulnerabilidade social e hipossuficientes, público alvo da Defensoria. A atuação da Defensoria Pública na qualidade de custus vunerabilis visa promover a observância dos direitos humanos aos envolvidos. Sobre essa modalidade de atuação, Maia (2017, p. 45) ensina que: custos vulnerabilis representa uma forma interventiva da Defensoria Pública em nome próprio e em prol de seu interesse institucional (constitucional e legal) - atuação essa subjetivamente vinculada aos interesses dos vulneráveis e objetivamente aos direitos humanos - representando a busca democrática do progresso jurídico-social das categorias mais vulneráveis no curso processual e no cenário jurídico-político.

Assim, a participação ativa do Ministério Público e da Defensoria Pública mostra-se essencial na construção de soluções para ações de natureza possessória, visto que viabiliza melhor diálogo entre as partes e articulações com os órgãos estaduais e municipais que devem efetivar a articulação de políticas públicas para as famílias em situação de vulnerabilidade social que serão afetadas com o cumprimento da decisão judicial, coadunando com os princípios da consensualidade e da cooperação.

Além disso, não raramente, ações possessórias servem de instrumento para diversas categorias de crimes, como as tentativas de grilagem de terras públicas, fraudes documentais e cartoriais (MARANHÃO, 2020a). Essas reforçam a grave falha quando as ações coletivas de natureza possessória são conduzidas sem a participação dos órgãos indicados pela própria lei processual.

Em outro momento, o CPC faz um novo apontamento sobre a importância da mediação para os conflitos possessórios. No art. $565 \S 1^{\circ}$, o legislador determina que, passado mais de um ano da decisão liminar que tenha determinado o despejo, o magistrado realize audiência de mediação com a presença dos demais atores já mencionados, para que seja oportunizada novamente a resolução consensual do conflito. Ora, certo da natureza complexa dos conflitos possessórios e dos diversos direitos fundamentais envolvidos, assim como a velocidade de alteração de uma ocupação, o Código prevê a retomada dos diálogos pelo consenso e da cooperação dos órgãos competentes. 
A propósito, convém destacar que a previsão de cooperação à resolução dos litígios possessórios coadunam com as disposições do Comentário Geral n. ${ }^{\circ} 07$ ao Pacto Internacional de Direitos Econômicos, Sociais e Culturais, produzido pela Comissão de Direitos Humanos da Organização das Nações Unidas, cujo parágrafo 16 propõe que, mesmo nos casos de despejos legalmente justificados, deve ser assegurada "uma autêntica oportunidade processual para que se consultem as pessoas afetadas" (OSÓRIO, 2014, P. 58). Ou seja, o texto indica a realização de audiência judicial para que os ocupantes possam ser ouvidos antes de qualquer decisão judicial, especialmente quando couber ordem de despejo.

O direito a uma oportunidade de autocomposição nas ações judiciais envolvendo conflito possessório pode ser reconhecido como uma eficácia jurídica ligada ao direito à moradia. Embora essa eficácia procedimental não substitua propriamente o direito à moradia, que assegure, por exemplo, medidas habitacionais ou de reassentamento, "pode-se afirmar que ela possui valor intrínseco, enquanto promove o acesso à justiça para pessoas em situação de vulnerabilidade habitacional e de insegurança na posse" (MELLO, 2017, p. 2079).

As tratativas de mediação, sejam judiciais ou extrajudiciais, tem o potencial de resolver dar boas resoluções aos conflitos quando privilegiados os princípios da consensualidade e da mediação, com a participação de todos os órgãos e instituições que possam contribuir para a formação de um resultado consensual. No caso das demandas envolvendo ocupações urbanas e, consequentemente, a tutela do direito à moradia, ressalta-se a necessidade de interveniência de múltiplos departamentos da Administração Pública na resolução do conflito, como os órgãos de habitação, urbanismo, meio ambiente, planejamento e saneamento básico. Nesse sentido, destaca-se que:

[...] o diálogo e a interação entre esses diferentes departamentos da Administração Pública certamente não pode ocorrer em atos judiciais como audiências e tampouco pode depender exclusivamente de impulso judicial. É preciso que haja um comprometimento efetivo do Poder Público para engendrar soluções policêntricas no interior da esfera administrativa e somente levar a juízo propostas já em estágio avançado de conclusão (MELLO, 2017, p. 2094).

Sem perder de vista a imprescindível participação dos órgãos públicos, destaca-se também a indispensabilidade de importantes atores da Sociedade Civil que acompanham os conflitos possessórios em seu dia a dia. Independentemente da formulação de estratégia para mediação de conflitos possessórios deve observar a necessidade de incorporação de cidadãos 
e associações para contribuir com o controle, deliberação e criação de estratégias (AVRITZER, 2008).

É com base nos princípios da consensualidade, da cooperação e da importância da intervenção multissetorial, inclusive da Sociedade Civil, para resolução dos conflitos possessórios, que foi instituída a Comissão Estadual de Prevenção à Violência no Campo e na Cidade (COECV) no Estado do Maranhão por meio da Lei Estadual n. ${ }^{\circ}$ 10.246/2015. O mecanismo, com 5 anos de existência, apresenta dados e metodologia de atuação com repercussão nacional, e passarão a ser analisados neste trabalho.

\section{A COECV COMO MECANISMO DE MEDIAÇÃO DE CONFLITOS POSSESSÓRIOS}

A Comissão Estadual de Prevenção à Violência no Campo e na Cidade - COECV teve início das atividades em agosto de 2015, a partir da publicação da Lei Estadual n. ${ }^{\circ}$ 10.246/2015, criada com o intuito de reduzir a violência em áreas de conflitos possessórios nas zonas urbanas e rurais e dar cumprimento às previsões do Decreto Estadual n. ${ }^{\circ}$ 31.048/2015, que impôs a obrigatoriedade da Polícia Militar do Maranhão comunicar à COECV sempre que houver uma decisão judicial de manutenção/reintegração de posse com requisição de uso de força policial.

O colegiado passou a ser composto, conforme previsto na Lei, por 11 membros fixos, sendo 07 órgãos estaduais a Secretaria de Direitos Humanos e Participação Popular (SEDIHPOP), que também coordena a Comissão), Secretaria de Segurança Pública (SSP), Secretaria de Cidades e Desenvolvimento Urbano (SECID), Secretaria da Agricultura, Pecuária e Pesca (SAGRIMA), Instituto de Colonização e Terras (ITERMA), Comando Geral da Polícia Militar (CGPMMA) e Defensoria Pública do Estado (DPE); e 04 entidades da sociedade civil indicadas pelo Fórum Estadual de Direitos Humanos do Maranhão, a Sociedade Maranhense de Direitos Humanos (SMDH), Comissão Pastoral da Terra (CPT), Federação dos Trabalhadores Rurais Agricultores e Agricultoras do Estado do Maranhão (FETAEMA) e a União por Moradia Popular (UMP).

Além desses, outros órgãos e entidades passaram a acompanhar e participar regularmente das discussões do colegiado na condição de membros convidados, como o Ministério Público Estadual, a Corregedoria de Justiça do Tribunal de Justiça do Maranhão, a Secretaria de Agricultura Familiar e a Secretaria de Igualdade Racial. 
A partir das previsões legais que fundamentam a atuação da Comissão e da posterior publicação do primeiro regimento interno da Comissão, em abril de 2016, o mecanismo passou a ser responsável por se manifestar a respeito do Estudo de Situação produzido pela PMMA, verificando a possibilidade de fazer uma mediação entre os envolvidos no conflito possessório e tomar outras medidas como, por exemplo, articular para que os requeridos tenham assistência jurídica no processo judicial ou que sejam realocados para um assentamento federal ou estadual. As competências de atuação da COECV e discussão em plenário são, a princípio, para tratar os conflitos possessórios cujas ocupações são coletivas e de caráter consolidado.

Quando da criação da Comissão, havia 296 ordens judiciais de reintegração/manutenção de posse pendentes de apreciação e despacho. Até dezembro de 2020, após quase 5 anos da criação da COECV, foram triados e analisados 695 processos judiciais com ordem de despejo, sendo que 516 já estão arquivados na Comissão e os outros 175 ainda estão em trâmite, em tratativas de mediação ou prevenção à violência. Os referidos números indicam que a atuação da COECV garantiu maior efetividade à resolução dessas pendências, seja mediando conflitos para uma solução amistosa, ou intervindo para minimizar os impactos das decisões judiciais.

Com o amadurecimento da Comissão, percebe-se a sua consolidação como importante mecanismo de prevenção à violência e mediação de conflitos possessórios no Estado. Como consequência, a atuação da Comissão tem sido cada vez mais abrangente, contribuindo para solucionar pacificamente conflitos de diversas naturezas, em todo o Estado, sob demandas de órgãos públicos, instituições do sistema de justiça e entidades da sociedade civil.

As novas demandas da Comissão, antes extraordinárias, motivaram a elaboração do novo regimento interno publicado em dezembro de 2020, ampliando as possibilidades de atuação da Comissão e refinando os seus procedimentos internos.

O desenvolvimento dos trabalhos do colegiado também resultou em outros aspectos importantes para a consolidação da política, como: atuação em conflitos socioambientais coletivos, consolidados ou não; fortalecimento de diálogo institucional com órgãos públicos, entidades da sociedade civil e instituições do sistema de justiça; reconhecimento da importância da COECV pelo poder judiciário maranhense e pela Corregedoria do TJMA; elaboração de minuta do Plano Estadual de Prevenção à Violência no Campo e na Cidade; 
início da discussão para elaboração de termos de cooperação com diversas instituições; acompanhamento de demandas extraordinárias, como providências após despejos e mediações de conflitos envolvendo comunidades tradicionais; demandas envolvendo violências institucionais e outras situações cujas naturezas atraem a atuação da Comissão.

A Comissão também tem a importante função de atuar como mecanismo de prevenção da violência em suas diversas formas, por buscar minimizar os impactos negativos consequentes de uma decisão de reintegração de posse, em observância aos direitos das partes e às determinações do Manual de Diretrizes Nacionais para a Execução de Mandados Judiciais de Manutenção e Reintegração de Posse Coletiva. Quando da denúncia de alguma violação de direitos humanos, a COECV também atua para articular a prevenção de novos conflitos e a reparação de eventuais violências.

Quanto à mediação, o procedimento estabelecido pela Comissão possibilita que as partes possam ter nova oportunidade de solucionar pacificamente o conflito, com a participação dos diversos órgãos e entidades membros do Colegiado. A mediação de conflitos conduzida pela COECV já resultou bons resultados e proporcionou a autocomposição em diversos casos.

Por entender que tratar de conflitos possessórios do Estado envolve diversas outras frentes de atuação, a Comissão conta com a contribuição e trabalho conjunto de outros setores da SEDIHPOP, como os sistemas de proteção, Superintendência de Combate à Violência Institucional, setor de proteção à pessoa idosa e Assessoria da Pessoa Indígena. Além disso, fortalece o diálogo e parceria com outros órgãos públicos e com diversas entidades da sociedade civil.

Durante os quase 5 anos de funcionamento, a COECV consolidou-se como uma importante política pública para a prevenção da violência no campo na cidade e mediação de conflitos possessórios no Estado. Reunindo importantes atores especializados nas áreas relacionadas à política, constatam-se grandes impactos no Estado, segundo os dados do Relatório 2019 (MARANHÃO, 2020b).

O primeiro aspecto que merece destaque é a redução do número de conflitos possessórios pendentes de manifestação do Estado. Quando criada, a COECV recebeu 296 mandados judiciais de reintegração/manutenção de posse para análise e despacho para cumprimento. Atualmente, após recebidas outras 399 novas ordens judiciais, a Comissão analisou, despachou e arquivou 520 processos, possuindo atualmente apenas 175 casos em 
trâmite - quantidade significativamente inferior ao momento de criação da Comissão, indicando melhor eficiência do Estado para o tratamento dessas demandas.

Em segundo lugar, destaca-se a prevenção à violência institucional no cumprimento de ordens de reintegração de posse: A Comissão impacta diretamente na prevenção aos excessos na atuação de agentes públicos, notadamente em relação ao disposto no Decreto Estadual n. ${ }^{\circ} 31.048 / 2015$. A COECV recomenda e monitora a regular atuação das forças de segurança, em conformidade ao Manual de Diretrizes Nacionais para a Execução de Mandados Judiciais de Manutenção e Reintegração de Posse Coletiva, observando, por exemplo, o dever de notificação prévia e o uso moderado da força. No caso do recebimento de denúncia sobre suposto excesso ou violência na atuação de algum agente público, a Comissão atua para encaminhar a denúncia, cobrar e monitorar a apuração da conduta do servidor pelos órgãos competentes.

Em seguida, a prevenção à violência em conflitos possessórios também é uma conquista do mecanismo. Desde o momento da triagem de nova demanda, a Comissão busca identificar indícios de acirramento de conflito ou riscos à vida de alguma das partes, para que possa atuar preventivamente de modo a resguardar a vida e a integridade física dos envolvidos. No caso do recebimento de denúncias, a atuação in loco da equipe e a articulação com SSP, com delegacias, com Ministério Público ou mediação direto com as partes contribuem significativamente para conter possíveis acirramentos de conflito entre as partes.

Destaca-se também a especialização do trabalho técnico da Comissão para contribuir com a resolução e mediação de conflitos: Com o passar dos anos, a Comissão adquiriu experiência para analisar conflitos, elaborar relatórios situacionais e conduzir tratativas de mediação entre as partes. De forma inédita no Estado, o colegiado reúne setores especializados em conflitos possessórios da sociedade, do poder público e do sistema de justiça para pensar, conjuntamente, em solucionar os conflitos possessórios no Maranhão. Como resultado, além das diversas vezes em que a Comissão contribuiu para solucionar conflitos, tem sido cada vez mais demandada para elaborar pareceres, relatórios e notas técnicas sobre novos casos.

Outro ponto de destaque é que a COECV contribui para a redução de ocupações com finalidade especulatória ou com motivações políticas. Ocupações com objetivo de especulação imobiliária ou destinada à finalidade política passaram a ser fortemente combatida pelos membros da Comissão. Os casos são rapidamente identificados e o colegiado 
intervém para impedir o mau uso do solo urbano. Como resultado, diminuíram significativamente a quantidade de denúncias dessa modalidade de ocupação, sobretudo em período eleitoral.

De outro lado, um dos aspectos mais relevantes, sobretudo considerando o contexto do Estado, é a mediação de conflitos socioambientais. Alguns conflitos socioambientais atraem a atuação da COECV para prevenir violência e evitar acirramentos e crimes ambientais, ainda que não possuam processos judiciais em trâmite. A atuação da Comissão tem contribuído para garantir segurança, acesso à justiça, apoio técnico e uma mediação qualificada para lidar com conflitos dessa natureza, como é o caso da duplicação da BR-135, conflito com as comunidades tradicionais de Alcântara, Pequiá de Baixo, situação pós-despejo das famílias de Barra da Onça, mediação com a comunidade de Cajueiro, comunidade indígena Tremembé e diversos outros.

Além do já exposto, a omissão procede com o recebimento e tratamento denúncias de violações de direitos humanos de diversas naturezas. A COECV se consolidou como porta de entrada de diversas denúncias de Direitos Humanos. Após triagem, os casos são encaminhados e acompanhados conjuntamente por outros setores, e órgãos, ou tratado pela própria equipe técnica.

Primando pela participação popular e democratização da Administração Pública, os trabalhos da Comissão desenvolvem o fortalecimento do diálogo com a sociedade civil. Além das quatro vagas da sociedade civil dentre os membros fixos da Comissão, a COECV hoje representa um importante setor do governo para dialogar e resolver demandas envolvendo conflitos fundiários e socioambientais. Constantemente a Comissão tem sido procurada por diversas entidades da sociedade civil para discutir e solucionar demandas em todo o Estado.

Merece relevo, ainda a construção de importante banco de dados sobre os conflitos possessórios do Estado. O banco de dados mantido pela equipe técnica possui uma enorme quantidade de informações sobre os conflitos possessórios judicializados e as ocupações do Estado, já tendo sido utilizados para realizar importantes diagnósticos e trabalhos acadêmicos visando conhecer os conflitos e a atuação das instituições do sistema de justiça.

Destaca-se, ainda, o relacionamento construído com o Poder Judiciário, em situação inédita no Estado. A Comissão fortaleceu a relação com o Tribunal de Justiça visando unir esforços para garantir a melhor resolução possível aos conflitos possessórios judicializados do Estado. Como fruto da relação, o Provimento 08/2019 da Corregedoria Geral de Justiça do 
Tribunal de Justiça do Estado do Maranhão prevê a atuação da COECV nos processos judiciais para contribuir de forma preventiva. Além disso, o compartilhamento de dados e os diálogos sobre a instalação da Vara Agrária representam um avanço no relacionamento entre os dois poderes.

Por fim, a construção do I Plano Estadual de Prevenção e Mediação da Violência no Campo e na Cidade, em vias de ser aprovada, representa a institucionalização da prevenção e mediação de conflitos como uma política de Estado, não de governo. O texto reunirá diversos atores para combater a violência no campo e garantir o adequado tratamento aos conflitos possessórios, notadamente pelo fortalecimento dos instrumentos de mediação extrajudicial e o incentivo à autocomposição judicial, conforme preceituado na doutrina processualista brasileira.

Frente aos dados e à metodologia de atuação da Comissão, bem como os marcos regulatórios e normativos, entende-se que a criação do colegiado de caráter intersetorial é eficaz para seu objetivo de tratamento e resolução de demandas possessórias. Em que pese as limitações inerentes às competências legais da Comissão e a complexidade dos conflitos possessórios de natureza coletiva, a redução da violência e os casos bem-sucedidos de mediação demonstram o significativo avanço no tratamento do Estado a litígios dessa natureza.

\section{CONSIDERAÇÕES FINAIS}

Ao se refletir sobre os conflitos possessórios é crucial compreender como as relações econômicas, os processos históricos de grilagem de terra e valorização econômica da propriedade privada impactam na compreensão das disputas.

A expansão do agronegócio aliada a formação irregular dos espaços urbanos e divisão desigual de terras, consolidou no Brasil um histórico violento de conflitos pela posse da terra em áreas urbanas e rurais Para além do direito à moradia, tais conflitos refletem processos políticos e econômicos de exclusão de grupos sociais vulneráveis, que são "empurrados" a ocupar irregularmente espaços vazios ou improdutivos, e depois sofrem processos violentos de expulsão e despejo.

Nesse contexto, a complexidade das disputas e o embate de forças econômicas e defesa dos direitos humanos ao chegarem ao judiciário se somam a uma complexidade 
jurídica que pode resultar graves injustiças, e porque vem sendo necessário que o Poder judiciário adote procedimentos preventivos que visem evitar as violências e de fato corroborar para a resolução desses conflitos.

O Código de Processo Civil vigente trouxe importantes inovações para o tratamento da jurisdição aos conflitos, dentre os quais destacamos o princípio da consensualidade, que incentiva a adoção dos métodos adequados de solução de conflitos, e a colaboração no processo, responsável por agregar importantes órgãos e instituições que possam contribuir para uma resolução consensual.

No que concerne às demandas coletivas possessórias, fica ainda mais evidente a predisposição das normas e doutrinas processualistas às estratégias de resolução de demandas de forma amistosa. O CPC prevê diversas estratégias para que o conflito seja pacificado com a adequação das vontades das partes, como a designação de audiência de mediação, intimação do Ministério Público, Defensoria Pública e dos órgãos públicos que possam contribuir. Destaca-se, aqui, o reconhecimento da complexidade dos conflitos possessórios que, longe de tratar somente sobre interesses individuais, envolve direitos difusos, sociais e coletivos, demandando múltiplos atores e estratégias para uma resolução adequada.

É ciente da complexidade dos conflitos e da vultuosa e crescente quantidade de litígios possessórios judicializados, que surge a oportunidade do Poder Executivo atuar para promover estratégias de mediação voltados à pacificação social. O Maranhão, estado com maior quantitativo de conflitos no país, estabelece a COECV como estratégia de prevenção da violência e mediação dos conflitos que, por vezes, não são resolvidos no poder judiciário - ou, quando resolvidos, não foi oportunizado um procedimento de mediação adequado.

Os resultados da Comissão, em seus primeiros 5 anos de atuação, surpreendem. Constata-se a redução significativa de conflitos pendentes de um tratamento adequado (MARANHÃO, 2020b), diversos casos solucionados de forma consensual, prevenção à violência e a consolidação de um espaço colegiado democrático, representativo e eficiente para unir atores importantes para solução dessas demandas e garantia de direitos básicos.

Apesar dos avanços, não há como negar a necessidade de criação de instrumento que vincule a responsabilidade coletiva e compartilhada de todos os setores adequados, como o Plano Estadual. Além disso, o modelo da COECV pode e deve inspirar iniciativas em todo o Estado para garantir melhor tratamento aos conflitos coletivos possessórios. 
Portanto, diante da experiência da COECV e das reflexões sobre mediação de interesses em conflitos possessórios, conclui-se que o adequado tratamento para resolução de conflitos perpassa, necessariamente, pelos princípios da consensualidade e da cooperação, com uma mediação estabelecida com a contribuição dos atores adequados, de forma democrática e dialogada.

\section{REFERÊNCIAS}

ALEXY, Robert. Teoria dos direitos fundamentais. Tradução de Virgílio Afonso da Silva. São Paulo: Malheiros, 2008.

AVRITZER, Leonardo. Instituições participativas e desenho institucional: algumas considerações sobre a variação da participação no Brasil democrático. Opinião Pública. Campinas, v. 14, no 1, p. 43-64, jun. 2018. Disponível em: https://www.scielo.br/scielo.php?script=sci_arttext\&pid=S0104-62762008000100002>. Acesso em 20 de mar. de 2021.

AZEVEDO, André Gomma de (Org.). Manual de mediação judicial. 6. ed. Brasília: Conselho Nacional de Justiça, 2016. Disponível em: <https://www.cnj.jus.br/wpcontent/uploads/2015/06/f247f5ce60df2774c59d6e2dddbfec54.pdf > . Acesso em 10 de mar.. de 2021.

BARROSO, Luis Roberto. Por uma cultura de menor litigiosidade. Revista Diálogos sobre Justiça, Brasília, n. 2, p. 8-15, maio/ago. 2014.

BRASIL. LEI No 13.105, DE 16 DE MARÇO DE 2015. Disponível em:< http://www.planalto.gov.br/ccivil_03/_ato2015-2018/2015/lei/113105.htm>. Acesso em: $16 / 04 / 2021$

Ministério Das Cidades. Conselho Das Cidades. Resolução Recomendada n⿳0 87, de 8 de dezembro de 2009. Recomenda ao Ministério das Cidades instituir a Política Nacional de Prevenção e Mediação de Conflitos Fundiários Urbanos. Diário Oficial da União, Brasília, 25 maio 2010, seção 1, n. 98, p. 88. Disponível em:<

https://urbanismo.mppr.mp.br/arquivos/File/resolucao_87_2009_concidades.pdf $>$. Acesso em: $16 / 04 / 2021$

Resolução no 125 de 29 de novembro de 2010. Dispõe sobre a Política Judiciária Nacional de tratamento adequado dos conflitos de interesses no âmbito do Poder Judiciário e dá outras providências. Disponível em: Acesso em: 15 fev. 2021.

COSTA, Amanda Cristina de Aquino; CHAI, Cássius Guimarães. CONFLITOS NO CAMPO, JUDICIALIZAÇÃO E POLÍTICAS PÚBLICAS DE MEDIAÇÃO NO ESTADO 
DO MARANHÃO. Revista de Direito Agrário e Agroambiental, v. 5, n. 1, p. 81-100, 2019.

LEFEBVRE, Henri. O direito à cidade. São Paulo: Centauro, 2001.

MAIA, Maurílio Casas. Legitimidades institucionais no Incidente de Resolução de Demandas Repetitivas (IRDR) no Direito do Consumidor: Ministério Público e Defensoria Pública: similitudes \& distinções, ordem \& progresso. Revista dos Tribunais. vol. 986. ano 106. págs. 27-61. São Paulo: Ed. RT, 2017, p. 45.

MARANHÃO. Assembleia Legislativa. Diretoria Legislativa. Lei $\mathbf{n}^{\mathbf{0}} \mathbf{1 0 . 2 4 6}$, de 29 de maio de 2015. Dispõe sobre a criação da Comissão Estadual de Prevenção à Violência no Campo e na Cidade COECV e dá outras providências. Disponível em:

<http://arquivos.al.ma.leg.br:8080/ged/legislacao/LEI_10246>. Acesso em: 09 abr. 2021.

Secretaria de Estado dos Direitos Humanos e Participação Popular. Coordenação de Prevenção a Violência no Campo e na Cidade. Banco de dados da Comissão Estadual de Prevenção à Violência no Campo e na Cidade. São Luís: fev. 2021. Não publicado.

Secretaria de Estado dos Direitos Humanos e Participação Popular. Desde a implantação da Coecv em 2015, Maranhão reduz pela metade o número de conflitos fundiários e agrários. Disponível em: <https://sedihpop.ma.gov.br/2020/04/07/desde-aimplantacao-da-coecv-em-2015-maranhao-reduz-pela-metade-o-numero-de-conflitosfundiarios-e-agrarios/> . Acesso em 10 abr. 2021.

Secretaria de Estado dos Direitos Humanos e Participação Popular. Relatório 2019. Comissão Estadual de Prevenção à Violência no Campo e na Cidade - COECV. v. 1, mar. de 2020. São Luís: COECV, 2020b.

MARICATO, Ermínia. Para entender a crise urbana. 1. ed. São Paulo: Editora Expressão Popular, 2015.

MARINONI, Luiz Guilherme; ARENHART, Sérgio Cruz; e MITIDIERO, Daniel. Curso de Processo Civil. Vol. 3. São Paulo: RT, 2015.

MELLO, Cláudio Ari. Direito à moradia e conciliação judicial de conflitos coletivos possessórios: a experiência de porto alegre. Revista de Direito da Cidade, Rio de Janeiro, vol. 09, no 4, p. 2072-2098, 2017. Disponível em: <https://www.epublicacoes.uerj.br/index.php/rdc/article/view/29663> . Acesso em 15 de abr. 2021.

ONU - ORGANIZAÇÃO DAS NAÇÕES UNIDAS. Direitos humanos: a desocupação forçada e os direitos humanos. Genebra, 2005. (Ficha Informativa sobre Direitos Humanos, n. 25). Disponível em: <http://www.gddc.pt/direitoshumanos/ Ficha_Informativa25.pdf> Acesso em: 16/04/2021. 
OSÓRIO, Letícia Marques. O direito à moradia como direito humano. In.: FERNANDES, Edésio e ALFONSIN, Betania Alfonsin (org). Direito à moradia adequada: o que é, para quem serve, como defender e efetivar. São Paulo: Forum, 2014, p. 39-84.

POMPEU, Gina Vidal Marcílio; MARTINS, Dayse Braga. A Autocomposição de Conflitos no Contexto do Neoprocessualismo Civil e o Princípio da Consensualidade. Revista Scientia Iuris, Londrina, v.22, n.2, p.85-114, jul/2018. Disponível em:

http://www.uel.br/revistas/uel/index.php/iuris/index Acesso em: 10 de abr. de 2021.

PRIETO, Gustavo Francisco Teixeira. Sob o império da grilagem. Revista Terra Brasilis (Nova Série) [Online], 8| 2017.

Disponível: <http://journals.openedition.org/terrabrasilis/2137; DOI :

10.4000/terrabrasilis.2137>. Acesso em mar. de 2021.

RONIK, Raquel. Guerra dos lugares: a colonização da terra e da moradia na era das finanças. $1^{\text {a }}$ Ed. São Paulo: Editora Boitempo, 2015.

SANTOS, Boaventura de Sousa. Para uma revolução democrática da justiça. Ed. $3^{\mathrm{a}}$. Rev. Ampl. 2010. Disponível em:<

http://sociologial.dominiotemporario.com/doc/REVOLUCAO_DEMOCRATICA_JUSTICA. pdf>

SANTOS, Milton. A urbanização brasileira. São Paulo: Editora HUCITEC, 2018.

TARTUCE, Flávio. Direito civil: Direito das Coisas. Vol. 04. Ed. 9ª Rev., atual. e ampl. Rio de Janeiro, RJ: Editora Forense, 2017. 